\title{
Cell Sources, Liver Support Systems and Liver Tissue Engineering: Alternatives to Liver Transplantation
}

\author{
Soo Young Lee, Han Joon Kim, Dongho Choi \\ Department of Surgery, Hanyang University College of Medicine, Seoul, Korea
}

The liver is the largest organ in the body; it has a complex architecture, wide range of functions and unique regenerative capacity. The growing incidence of liver diseases worldwide requires increased numbers of liver transplant and leads to an ongoing shortage of donor livers. To meet the huge demand, various alternative approaches are being investigated including, hepatic cell transplantation, artificial devices and bioprinting of the organ itself. Adult hepatocytes are the preferred cell sources, but they have limited availability, are difficult to isolate, propagate poor and undergo rapid functional deterioration in vitro. There have been efforts to overcome these drawbacks; by improving culture condition for hepatocytes, providing adequate extracellular matrix, co-culturing with extra-parenchymal cells and identifying other cell sources. Differentiation of human stem cells to hepatocytes has become a major interest in the field of stem cell research and has progressed greatly. At the same time, use of decellularized organ matrices and $3 \mathrm{D}$ printing are emerging cutting-edge technologies for tissue engineering, opening up new paths for liver regenerative medicine. This review provides a compact summary of the issues, and the locations of liver support systems and tissue engineering, with an emphasis on reproducible and useful sources of hepatocytes including various candidates formed by differentiation from stem cells.

Keywords: Hepatocyte, Stem cells, Liver, Bioartificial liver, Liver tissue engineering, Bioprinting

\section{Introduction}

The liver is the largest organ in the human body, with a complex architecture and many functions. Its major functions are homeostasis, glucose and lipid metabolism, detoxification, production of serum proteins, and secretion of bile. Hepatocytes, comprising $80 \%$ of the liver volume and $50 \sim 60 \%$ of liver cells, play a central role in liver function and have a capacity for regeneration (1). When

\footnotetext{
Accepted for publication May 4, 2015, Published online May 30, 2015 Correspondence to Dongho Choi

Department of Surgery, Hanyang University College of Medicine, 17 Haendang-dong, Seongdong-gu, Seoul 133-792, Korea

Tel: +82-2-2290-8449, Fax: +82-2-2281-0224

E-mail: crane87@hanyang.ac.kr

(c) This is an open-access article distributed under the terms of the Creative Commons Attribution Non-Commercial License (http://creativecommons.org/ licenses/by-nc/4.0/), which permits unrestricted non-commercial use, distribution, and reproduction in any medium, provided the original work is properly cited.
}

hepatocytes are extensively damaged, liver function decreases causing liver failure. Liver failure, in association with multiple organ failure, is a significant cause of morbidity and mortality for which liver transplantation is considered the ultimate treatment. However, a shortage of donors, the relatively risky operation and the high cost reduce the benefits of liver transplantation. Liver diseases account for $2.5 \%$ of total deaths in the world, and their incidence and the health burden they impose are continuously increasing (2). To fill the gap between organ availability and demand, and to reduce the health burden, alternatives to liver transplantation are urgently needed. Cell transplantation, liver support systems and liver tissue engineering are potential alternatives. Successful cell transplantation hinges on finding adequate sources of cells capable of engrafting and proliferating to reconstitute the recipient organ. Since primary hepatocytes are the preferred cells but proliferate poorly in vitro, microenvironments promoting their multiplication are also being in- 
tensively investigated. In addition, bio-artificial liver devices, tissue engineering products created by seeding cells into decellularized organ scaffolds, as well as 3-D bioprinting, also require an effective and reproducible source of hepatocytes. Recently, hepatocytes differentiated from stem cells have shown great promise in cell-based therapy. In addition to being alternatives to organ transplantation, liver tissue engineering and stem-cell-derived hepatocytes may provide new approaches to toxicology and drug screening (3). In this review, we will describe the various types of cells available for cell transplantation, including those based on stem cells, and summarize recent advances in liver support systems and liver tissue engineering.

\section{Cell sources}

Major challenges in liver support therapy are the limited availability and efficacy of cell sources. Various cell types are being investigated as efficient sources of hepatocytes for liver support system, cell transplantation and tissue engineering. Among them are primary human and porcine hepatocytes, tumor-derived and immortalized cell lines, adult and embryonic stem cells, fetal hepatoblasts, oval cells and stem cell-derived hepatocyte-like cells (Table 1).

\section{Primary human hepatocytes and hepatocyte transplantation}

Primary human hepatocytes are used for hepatocyte transplantation by direct infusion of isolated cells, which has advantages over whole organ transplantation in being less invasive, less expensive, and more reproducible. There have been numerous animal studies and clinical trials investigating the use of this procedure in metabolic liver diseases, acute hepatic failure and chronic liver diseases.

Among the results from the studies of treating Wilson's disease and other metabolic liver diseases, those obtained for tyrosinemia, hypercholesterolemia, Crigler-Najjar syndrome and urea cycle defects are the most promising. The consequences of a single gene mutation can be treated by grafting hepatocytes expressing the gene, since production of only $5 \sim 15 \%$ of the missing protein can be enough to correct the deficiency. Up to 2012, 10 cases of urea cycle disorders that had been treated by hepatocyte transplantation have shown a reduction in ammonia levels, although most of the patients had eventually to receive orthotopic liver transplants (OLT) due to decreased efficacy over time (4). These results are promising in that hepatocyte transplantation is effective at least for temporary treatment of various metabolic liver disorders.

Table 1. Characteristics of various potential cell sources

\begin{tabular}{|c|c|c|c|}
\hline Cell type & Usage & Benefits & Limitations and risks \\
\hline Primary human hepatocytes & Cell transplantation & Compatibility & $\begin{array}{l}\text { Limited availability, } \\
\text { Difficult isolation, } \\
\text { Poor in-vitro multiplication } \\
\text { Rapid functional deterioration }\end{array}$ \\
\hline Porcine hepatocytes & Bioartifical liver & Availability & $\begin{array}{l}\text { Functional deterioration in vitro } \\
\text { Limited biocompatibility } \\
\text { Immunogenicity } \\
\text { Risk of xenozoonoses }\end{array}$ \\
\hline \multicolumn{4}{|l|}{ Cell lines } \\
\hline $\begin{array}{l}\text { Tumor-derived cell lines } \\
\text { Immortalized cell lines }\end{array}$ & Bioartifical liver & Unlimited expansion potential & $\begin{array}{l}\text { Low functional activity } \\
\text { Possible tumorigenic activity }\end{array}$ \\
\hline Human fetal hepatocytes & Cell transplantation & Extensive in vitro proliferation & $\begin{array}{l}\text { Ethical issues } \\
\text { Limited availability } \\
\text { Possible tumorigenicity }\end{array}$ \\
\hline $\begin{array}{l}\text { Oval cells } \\
\text { Stem cells }\end{array}$ & Cell transplantation & Bi-potent, Liver stem cell & Controversy over existence \\
\hline $\begin{array}{l}\text { Embryonic stem cells } \\
\text { Mesenchymal stem cells } \\
\text { Induced-pluripotent stem cells }\end{array}$ & Cell transplantation & $\begin{array}{l}\text { Pluripotency, } \\
\text { Proliferation capacity }\end{array}$ & $\begin{array}{l}\text { Lack of standardized protocol for } \\
\text { obtaining scalable amounts of } \\
\text { differentiated cells } \\
\text { Poor understanding of differentiation } \\
\text { process }\end{array}$ \\
\hline Induced hepatocyte-like cells & $\begin{array}{l}\text { Needs more inves- } \\
\text { tigation }\end{array}$ & $\begin{array}{l}\text { Bypassing complicated steps } \\
\text { Autologous source } \\
\text { Less tumorigenic }\end{array}$ & Functional stability and safety not proven \\
\hline
\end{tabular}


By contrast, the results of clinical studies of hepatocyte transplantation for acute liver failure aimed at bridging the time gap prior to OLT are not promising, as such (4). The number of hepatocytes that can be transplanted safely in acute liver failure has not been sufficient to restore hepatic function. It is also doubtful whether functional engraftment would be achieved on a clinically relevant time scale in the acute setting. Besides, about $40 \%$ of patients with acute liver failure recover spontaneously with only medical management (5).

Clinical investigations in chronic liver disease have yielded even worse results due to the fact that the damaged parenchymal architecture is far from ideal for the engraftment of sufficient numbers of cells. Currently, no further clinical studies are being carried out in this area (4). However, a study by Yovchev et al. (6) on a rat model showed that transplanted epithelial stem and progenitor cells could repopulate the lost liver parenchymal cells that had been replaced with fibrotic tissue, and had antifibrotic effects, which raised the hope for patients with liver cirrhosis. Komori et al. (7) have examined the possibility of transplanting hepatocytes into other organs instead of into livers that are not suitable for engraftment due to chronic disease or acute failure. In their experiments, direct injection of hepatocytes into a single lymph node rescued mice with fatal metabolic liver disease by generating a sufficient ectopic mass of liver. Ectopic hepatocyte transplantation could open new vistas for hepatocyte transplantation research aimed at saving patients with end-stage cirrhotic liver disease.

Nonetheless, various barriers must be overcome before hepatocyte transplantation can be accepted as a routine clinical treatment (8). Even though a single donor liver can provide enough hepatocytes for multiple recipients, and marginal or neonatal donors not suitable for whole-organ transplantation can be used, the lack of an adequate source of viable hepatocytes limits the wider application of clinical hepatocyte transplantation (9). Moreover, primary adult hepatocytes have a minimal ability to multiply in vitro and rapidly lose their structure and function after isolation. In vitro models such as sandwich and spheroid cultures have been developed to prevent functional deterioration of hepatocytes (10), but adult hepatocytes in culture are still not able to express all differentiated functions and often lack many enzymes, transporters, and cytochrome P450 enzymes. The engraftment and long-term survival of hepatocytes also need to be improved (9). In addition, immunosuppressive treatment accompanying hepatocyte transplantation has not yet been optimized (11). Therefore, the search for alternative cell sources of both hepatic and non-hepatic origin has received much attention (12). Likely sources are hepatocyte cell lines, xenogeneic hepatocytes and hepatocytes derived from stem or fetal cells.

\section{Porcine hepatocytes}

Porcine hepatocytes are most frequently used in bioartificial livers (BAL) and implantable devices as porcine livers are readily available and their hepatocytes are metabolically similar to human liver cells. Such xenogeneic cells are effective for cell transplantation under specific pathogen-free conditions. Transplanted porcine hepatocytes were metabolically active for more than 80 days in a Cynomolgus monkey model submitted to an effective immunosuppression regime (13). In addition to their availability, porcine hepatocytes seem to be less immunogenic than whole organ transplant, so that xenotransplantation is a potential solution for hepatocyte transplantation (14). However, transfer of zoonotic diseases (15), protein-protein incompatibility between species and possible immune responses generated during treatment remain challenges for the use of xenogeneic hepatocytes (16). The physiologic disparity between humans and pigs compels the search for alternative cell sources.

\section{Human hepatocyte cell lines}

In order to enhance cell availability and in vitro proliferation, tumor-derived hepatocyte cell lines and immortalized cells have been investigated. While they have unlimited expansion potential, these cell lines also have low activities for some essential hepatocyte functions (17). Human tumor-derived cell lines can be used in BALs. For example, the Extracorporeal Liver Assist Device (ELAD) uses the cell line C3A, which was developed from HepG2, a human hepatoma cell line (18). Studies have shown that C3A cells synthesize elevated levels of albumin and alpha fetoprotein, and have high nitrogen-metabolizing ability as well as being capable of multiplying extensively. However, their ammonia removal, amino acid metabolism, cytochrome P450s and drug-metabolizing functions remain low mainly because of the absence of the complete urea enzyme complex and reduced numbers of mitochondria (19). A pilot controlled clinical trial of the C3A cell line yielded no improvement in survival and biochemical parameters (20). The possibility of transmitting tumorigenic products or agents and possible complications arising from this are other major concerns (21). Immortalized human hepatocyte cell lines have been developed by trans- 
fection of primary hepatocytes with Simian Virus $40 \mathrm{~T}$ antigen (SV40 $\mathrm{T}$ antigen) in the hope that they would be more functional than HepG2, while proliferating rapidly (22). However, these cell lines have similar low activities, and the risk of potential tumorigenic effects remains and limits their use as implantable tissue (17). Therefore, it is important to develop systems whose growth can be tightly regulated so as to prevent malignant transformation. One approach involves reversible immortalization, in which retrovirus-transferred oncogenes (SV 40T antigen) are excised by site-specific Cre/LoxP recombination after immortalization. In addition, inserting a suicide gene such as HSVTK to make the immortalized cells sensitive to anti-viral drugs such as Ganciclovir has been suggested as a safeguard against possible uncontrolled tumorigenic effects of oncogenes (23). However, potential obstacles include possible inhibition of suicide gene transcription by promoter methylation and DNA damage accompanying Cre/lox recombination. More extensive research is needed to ensure the long-term safety and fully differentiated function of these cell lines.

\section{Human fetal hepatocytes}

Human fetal hepatocytes have a higher proliferation capacity than adult hepatocytes when transplanted, as well as in vitro. Hence they have been immortalized by transfection (SV40T, hTERT) (24) to increase their availability (25). However, fetal hepatocytes are not suitable to be employed in clinical treatment regimens in BALs, as they have lower capacities for ammonia elimination (49\%) and urea production $(1.1 \%)$ than primary hepatocytes. Human fetal liver cells have yielded modest clinical improvements in acute liver failure in a few studies $(26,27)$, and fetal liver transplantation has shown some promise (28). However problems with the availability of fetal hepatocytes, their possible tumorigenicity and their incompletely differentiated nature remain to be resolved before they can be used clinically, and ethical concerns need also to be addressed (29).

\section{Oval cells}

In the field of liver regeneration, oval cells have been suggested as hepatic stem/progenitor cells that proliferate rapidly when hepatocytes are exhausted due to prolonged injury, or when their multiplication is experimentally inhibited (30). Anatomically, these cells reside in the area called canals of Hering, which are terminal branches of biliary trees, and produce a mixture of the molecular markers of adult hepatocytes, cholangiocytes and fetal hepatoblasts (31). In the rat model of liver injury involving 2-acetylaminofluorene and partial hepatectomy, oval cells gave rise to hepatocytes and bile duct cells and expressed spatio-temporally specific hepatocyte and cholangiocyte lineage markers (32). As in adult hepatocytes, the repopulation capacity of oval cells is low in livers when the transplanted cells have no selective advantage (33) but when they are transplanted into FAH-deficient mice, these cells repopulate the liver as efficiently as adult hepatocytes (34). There has been widespread agreement that oval cells are the progeny of some kind of adult hepatic stem cell, though the nature of this stem cell population is unclear (35). However, a recent study has provided evidence that hepatocytes are not derived from oval cells but only from preexisting hepatocytes (36). It is not known whether this shift in paradigm is applicable to the human liver as well. The potential of oval cells for self-renewal, binary differentiation, and functional tissue replacement remains open to question in the light of these conflicting reports.

\section{Stem cells}

Adult, embryonic and induced pluripotent stem cells have all been intensely studied for their ability to differentiate into liver cells. Unlike primary hepatocytes, their high proliferation potential along with their pluripotency makes them scalable for cell-based therapy and tissue engineering. However, which stem cell populations are most promising clinically remains unclear.

\section{Adult stem cells (Mesenchymal stem cells, BM derived hepatocytes)}

Adult stem cells of non-hepatic origin are often preferred for stem cell-based therapies, cell transplantation and implantable devices, since they carry no risk of teratoma formation and are of less ethical concern than embryonic stem cells. Bone marrow (BM)-derived hematopoietic stem cells have been investigated as possible sources for hepatocyte differentiation, and were found to be as effective as adult hepatocytes in repopulating the liver in the FAH-deficient mouse model (37). However, correction of the deficiency was attributable to fusion of host hepatocytes with the introduced BM-derived cells, not to transdifferntiation of the latter (38). Indeed BM-derived hematopoietic stem cells contributed little to hepatocyte formation. On the other hand, another stem cell population called mesenchymal stem cells (MSC), derived from bone marrow and other locations including cord 
blood and adipose tissue, is being investigated for use in the treatment for liver diseases. MSCs, also known as multipotent adult progenitor cells (MAPCs) or multipotent mesenchymal stromal cells, which are plate-adhering, fibroblast-like cells, display hepatogenic and biliary differentiation potential in vitro (39) and have shown evidence of reducing inflammation and improving the clinical scores of liver disases $(40,41)$. In animal studies, direct injection of MSCs into damaged liver was able to generate hepatocyte-like cells. Human MSCs from bone marrow displayed the characteristic cuboidal morphology and specific capabilities of hepatocytes, such as glycogen storage and urea synthesis following activation of hepatocyte-specific gene promoters in vitro. When transplanted into the livers of immune-deficient mice, these cells repaired the injured liver by engrafting mainly in the periportal region of the liver lobule. After regional integration, they retained the abilities of hepatocytes to store glycogen and produce phosphoenolpyruvatecarboxykinase, connexin 32, albumin, and the human hepatocyte-specific antigen, HepParl (42). While in vivo hepatic repopulation through transplantation of MSCs needs further confirmation, the trans-differentiation of MSCs to myofibroblasts at the site of liver injury has aroused major concerns (43), and efforts have been made to prevent the possible formation of myofibroblasts and increase the repopulation efficacy $(44,45)$. Obtaining sufficient quantities of mature hepatocytes from stem cells for clinical treatment is a challenge that none of the available protocols is able to meet. Also, the current protocol for inducing differentiation involves complex growth factors and supplements, which increases the cost of the therapy. Hopefully, as recent studies on the therapeutic effects of MSCs in acute liver failure and cirrhosis suggest, the regenerative outcomes will turn out to be mainly due to the release of trophic and immunomodulatory factors such as IL-10 rather than to hepatocyte repopulation (46).

\section{Embryonic and induced pluripotent stem cells}

Embryonic stem cells (ES cells) have advantages over other cell sources due to their ability to differentiate into cells of all three germ cell layers, and their high capacity for proliferation in vitro. There are several reports of the differentiation of ES cells into hepatocyte-like cells that can be used in bioartificial liver (BAL) devices that buy time for liver transplantation and allow a diseased liver time to recover, without the potential zoonoses associated with using porcine hepatocytes (47). However, current protocols have failed to perform on a large scale, thus lim- iting further application of ES-derived hepatocytes in BALs. Other issues about using ES cells for cell based therapy are concerns about immunocompatibility and possible teratoma formation by non-differentiated cells, as well as ethical considerations (48). In order to avoid the ethical and immune issues raised by the use of ES cells, procedures have been developed for inducing pluripotent stem (iPS) cells to develop from fibroblasts or cells of other embryonic germ cell layers by manipulating them genetically to express oncogenic genes (49). Efforts to develop iPS cells into hepatocytes by exploiting small molecules or mechanical stress to induce their maturation into hepatocyte-like cells have raised the possibility of ex vivo maturation (50). However, despite these remarkable developments, the use of viral vectors, alterations of cell cycle regulation, and risk of teratoma formation all hinder the application of iPS cells in liver regenerative therapy (51). However, ES and iPS cell-derived hepatocytes and other cell lineages will be useful in pharmacological research and toxicity screening studies and may eventually play a role in cell based therapies (Fig. 1) (52).
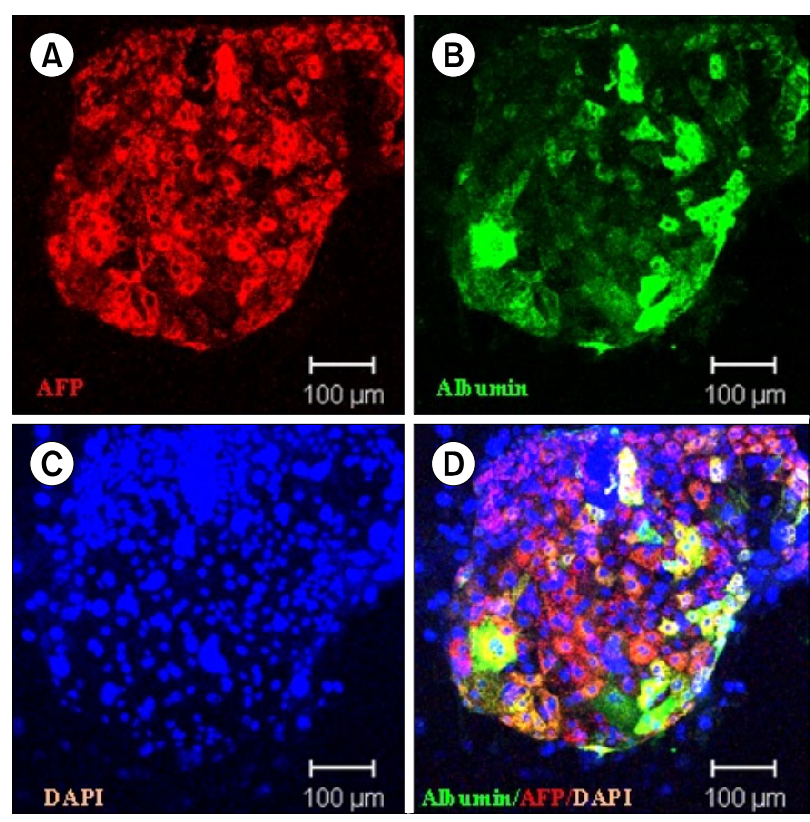

Fig. 1. Undifferentiated human ES cell derived hepatocyte colony was made by coculture on mitomycin treated NIH 3T3 J2 cells. AFP (A) and albumin (B) were stained with the hepatocytes in the colony. Nuclear staining (C) and merged image (D) showed various differentiation status of human ES derived hepatocytes (magnification; x200) (54). 


\section{Induced hepatocyte-like cells, hepatoblast-like cells (Direct differentiation)}

Induced hepatocyte-like cells (iHep) are cells derived directly from nonhepatic adult cells such as fibroblasts. In an animal study, mouse fibroblasts were directly reprogrammed by the combined expression of various transcription factors, including Hnf4a plus Foxa1, Foxa2, or Foxa3 (53), and Gata4, Hnfla, and Foxa3 along with inactivation of $\mathrm{p} 19^{\mathrm{ARF}}$ (54). This technique has the great advantage of bypassing complicated steps such as generating iPS cells and developing them into functional hepatocytes. iHep cells are morphologically similar to adult hepatocytes and express hepatic genes in response to over-expression of the above-mentioned hepatocyte lineage transcription factors. In murine models, iHep cells were capable of engrafting in diseased livers and reconstituting hepatic tissue, so rescuing the lethal phenotype of $\mathrm{Fah}^{-/}$ mice $(53,54)$. Like iPS cells, these hepatocyte-like cells might provide an autologous source of stem cells that would not require immune suppression. Promisingly, reprogramming of human fibroblasts to hepatocytes possessing key metabolic functions was also achieved by expressing FOXA3, HNF1A, and HNF4A (55) or a combination of HNF1A, HNF4A, and HNF6 together with the maturation factors ATF1, PROX1, and CEBPA (56). These reprogrammed cells possess the theoretical advantages of being less likely to form tumors since they are generated from fibroblasts without going through a pluripotent stage, and of not expressing the pluripotency genes OCT4 and NANOG (57). This direct reprogramming strategy has also been applied to mouse embryonic fibroblasts, producing hepatoblast-like cells called induced hepatic stem cells (iHepSCs) by introducing Hnflb and Foxa3 (58). These iHepSCs were able to differentiate into both hepatocytes and cholangiocytes in vitro and in vivo, suggesting that they could be an expandable source of functional hepatocytes. Though the ability to generate functional hepatocytes or hepatic stem cells from pluripotent/multipotent cells, or from reprogrammed somatic cells, is encouraging, more investigation of their final differentiation, functional stability and safety is needed before these cells can be used in liver tissue engineering.

\section{Functional stability of isolated hepatocytes in vitro}

The rapid functional deterioration of primary isolated hepatocytes and hepatocytes differentiated from either ES or iPS cells is the major obstacle to using them as cell sources. Since hepatocyte function is plastic and largely regulated by the surrounding, the effects of extracellular signaling molecules, cell-cell interactions, cell-matrix interactions and physical factors are being intensively investigated (59). The approaches being tried include culture on arginine-free medium, on floating collagen membranes, on various types of extracellular matrix materials, and in the presence of dimethyl sulfoxide. Extracellular matrices resembling the architecture of the hepatic perisinusoidal space, and co-culture of hepatocytes with non-parenchymal cells, have been the favorite strategies for mimicking in-vivo conditions (60). Interestingly, collagen-sandwich systems have been found to be capable of maintaining cell morphology, such as the formation of bile canaliculi, and the secretion of albumin and transferrin for extended periods, while the cells survive for longer than in monolayer gels (Fig. 2) (61). Microarray gene expression analysis has shown that "double gel" culture is superior to single layer culture in terms of metabolic and synthetic functions (62). The stable long-term retention of mature liver functions, such as albumin secretion, cytochrome P450 enzyme activity (63), and production of junctional complex proteins, is strongly influenced by cell-cell interactions in co-cultures, though the mechanism involved are unknown (64). In order to generate the heterotypic interaction between liver parenchymal cells and non-parenchymal cells, which has a profound role in liver physiology, various liver-derived cells such as biliary epithelial cells and stellate, endothelial and Kupffer cells have been co-cultured with

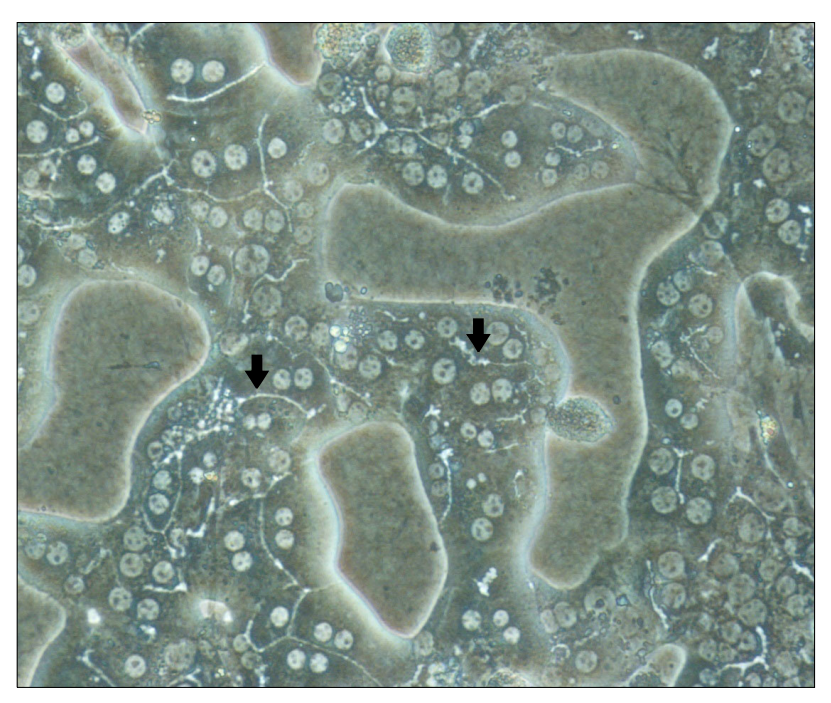

Fig. 2. Typical morphology of the cultured mouse hepatocytes with collagen double gel culture system. Arrows indicate bile canaliculi structure within mouse hepatocytes and cultured hepatocytes showed polygonal shape. Binuclear hepatocytes were present with very clear cytoplasmic margin (magnification; x200) (63). 
hepatocytes. Non-liver derived cells such as human fibroblasts, aortic endothelium, lung epithelium and dermal fibroblasts are also candidates for co-culture (65). Approaches that do not mimic the biological situation are also being investigated, such as co-culture with non-liver derived cells, use of non-biological subcellular components and 3D cultures (66). The development of a culture model that maintains the phenotypic stability and scalability of hepatocytes could improve BAL design and provide improved platforms for the study of hepatic function.

\section{Liver support systems}

Liver support systems are extracorporeal devices, categorized as non-biological and bio-artificial liver support systems, which support regeneration of the patient's liver and buy time until a suitable donor organ is available. The goal of these support devices is to replace liver function in patients with acute, acute-on-chronic and end-stage chronic liver failure. While the non-biological liver support systems are only designed to perform the role of detoxification not the synthetic and metabolic functions of the liver, the bio-artificial systems contain living cells and bioreactors that can carry out these additional roles.

\section{Non-biological liver support systems}

The idea behind artificial liver support systems is that acute liver failure or acute on chronic liver failure can be treated by filtering and adsorbing accumulated toxins not cleared by the nonfunctioning liver (46) These systems are based on the same concept as kidney dialysis systems, and purify the blood by albumin dialysis or plasma separation and filtration. They remove not only water-soluble substances, but also lipophilic, albumin-bound substances, such as bilirubin, bile acids, metabolites of aromatic amino acids, medium-chain fatty acids and cytokines. Clearance of those substances that inhibit liver regeneration and cause damage to other vital organs such as brain, kidney, lung and heart is important. The Molecular Adsorbent Recirculating System (MARS, Gambro Americas, Lakewood, CO), Plasma Separation Adsorption and Dialysis system (Prometheus, Fresenius Medical Care, Bad Homburg, Germany), single-pass albumin dialysis (SPAD), and selective plasma filtration therapy (SEPET) are included among these systems. The MARS and Prometheus have been widely used at the bedside. The former consists of a double-circuit system, one circuit with a haemodiafilter and the other with albumin as the acceptor for albumin-bound toxins, which can remove both water soluble and lipophilic molecules. Although studies have shown positive effects on liver failure (67), this device is mainly used to supply a temporary bridging function. The fractionated plasma separation and adsorption system (Prometheus) is also a double-circuit system, and consists of a blood circuit and a plasma circuit separated by an albumin-permeable polysulfone membrane. The plasma fraction passes into the absorbents that comprise an anion exchanger and a neutral resin in which the albumin-bound toxins are directly purified, while the blood circuit is exposed to high-flux dialysis to remove water soluble toxins (68). Although the Prometheus has proven to be efficient at lowering serum levels of bilirubin, bile acids, ammonia, creatinine and urea without affecting hemoglobin and platelet levels (69), no statistically significant improvement in survival of patients treated with these devices has yet been demonstrated.

\section{Bioartificial liver support systems (BALs)}

Though artificial livers can remove liver toxins up to a point, their inability to carry out the metabolic functions of the liver such as ureagenesis, protein synthesis, gluconeogenesis, enzymatic detoxification, and immune modulation makes it difficult for them to replace a nonfunctioning liver. Thus, bioartificial liver systems, which incorporate living liver cells into an extracorporeal device, are regarded as the ultimate liver support system by many investigators. In order to perform functions other than detoxification, viable hepatocytes are placed in a 3D network of hollow fibers designed for plasma perfusion. The bioreactors have been specifically developed to provide optimal conditions for the activities of living liver cells. More importantly, they permit the growth of hepatocytes and are easy to handle. There exist several bioartificial liver support devices designed for clinical use, and they generally employ primary porcine hepatocytes, human hepatocytes or tumor-derived cell lines. The HepatAssist ${ }^{\mathrm{TM}}$ system (Alliqua Inc., Langhorne, PA, USA), the most widely used BAL device, used cryopreserved porcine hepatocytes within a modified dialysis cartridge where the patients' plasma encounters the hepatocytes across a microporous membrane. This device was proved to be safe, and provided a survival benefit to a subgroup of fulminant and subfulminant hepatic failure patients, in a large multicenter phase $2 / 3$ RCT (70). In a similar set-up, the Extracorporeal Liver Assist Device $\left(\right.$ ELAD $^{\circledR}$; Vital Therapies Inc., San Diego, CA, USA) uses the immortalized hepatoblastoma cell line $\mathrm{C} 3 \mathrm{~A}$, which provides liver enzymatic activities and was found to improve bilir- 
ubin and ammonia levels and hepatic encephalopathy (71). Other designs of BAL include the AMC-BAL (Academic Medical Center, Amsterdam, Netherlands) and the MELS (Modular Extracorporeal Liver Support System, Charité, Berlin, Germany), whose clinical efficacy is being evaluated $(72,73)$. However, the membranes separating cells from plasma are unable to achieve sufficientin-vivo perfusion rates, and there is a lack of sources of reliable, safe, functionally active and strongly proliferating human cells. These factors prevent the BAL from being the ultimate liver support system (74). Hence, cell transplantation and bioengineering concepts are being investigated that would permit closer contact between hepatocytes and patients' blood, to allow for better mass exchange (73).

\section{Decellularization-Recellularization}

In the field of bioengineering, perfusion-decellularization is the most reliable method of obtaining decellularized whole-organ scaffolds for use as structures for organ bioengineering. During decellularization, cells and other immunogenic molecules such as DNA and alpha-Gal epitopes are removed and the extracellular matrix remains as a scaffold for the seeding of candidate cells. 3D microstructure is very important for liver function, because it provides a vascular framework and biliary system. The extracellular matrix proteins are unlikely to induce immune reactions, even in allogenic or xenogenic systems, since they are considered to be highly conserved across species (75). It has been possible to repopulate a non-immunogenic biomatrix of porcine livers with the autologous cells of a patient waiting for a liver transplant. Badylak and his group (76) were the first to propose a qualitative definition of the term decellularization. Currently, the decellularization of livers to obtain the extracellular matrix is primarily achieved by perfusion with alkaline detergents in combination with enzymatic agents (76). Recellularization strategies combine current cell isolation and culture techniques with methods developed for extracorporeal organ perfusion: after seeding cells into the decellularized liver matrix, the neo-organ goes through maturation and after maturation in the bioreactor, the bioengineered graft can be implanted without a requirement for lifelong immunosuppressive therapy and its numerous adverse effects. Uygunet. al. were the first to publish a study of the implantation of a recellularized liver graft in rat liver transplantation models (77). Soto-Guiterez, and Baptista have also been achieving progress in the decellurization-recellularization method using animal models $(78,79)$. Recently, Barakat et al. developed a humanized liver organ using decellularized porcine liver and human fetal hepatocytes co-cultured with human fetal stellate cells (80). The greatest advantage of this technique in comparison with other tissue engineering approaches that require the reconstruction of vascular integrity, is the fact that a vascular framework is retained during decellularization. In relation to recellularization, the variety of potential cellular sources derived from embryonic, fetal or autologous induced pluripotent stem cells creates new possibilities. However, further evaluation to ensure clinically relevant safety and efficacy is needed in order for this technique to be an alternative route to overcoming the shortage of organs for organ transplantation and the burden of lifelong immunosuppressive therapy.

\section{Bioprinting of liver}

$3 \mathrm{D}$ bioprinting is a recent advance in tissue engineering that enables the accurate construction of complex parenchymal organ structures, including a complex vascular tree network (81). The idea of printing biological materials such as collagen, fibronectin suspensions and cells was first suggested by Klebe in 1988 (82). Recent 3D organ printing uses additive biofabrication techniques to build 3D spheroids by a layer-by-layer approach using cell suspensions as liquid "bioink" (83). For hepatic constructs, Robbins et al. introduced metabolically active 3D hepatic tissue built by the NovoGen MMX Bioprinter ${ }^{\mathrm{TM}}$ (Organovo Holdings, Inc., San Diego, CA, USA). These workers achieved increased liver specific function lasting for up to $135 \mathrm{~h}$, and compartment-specific organization, along with a primitive hepatocyte microanatomy of hepatic stellate

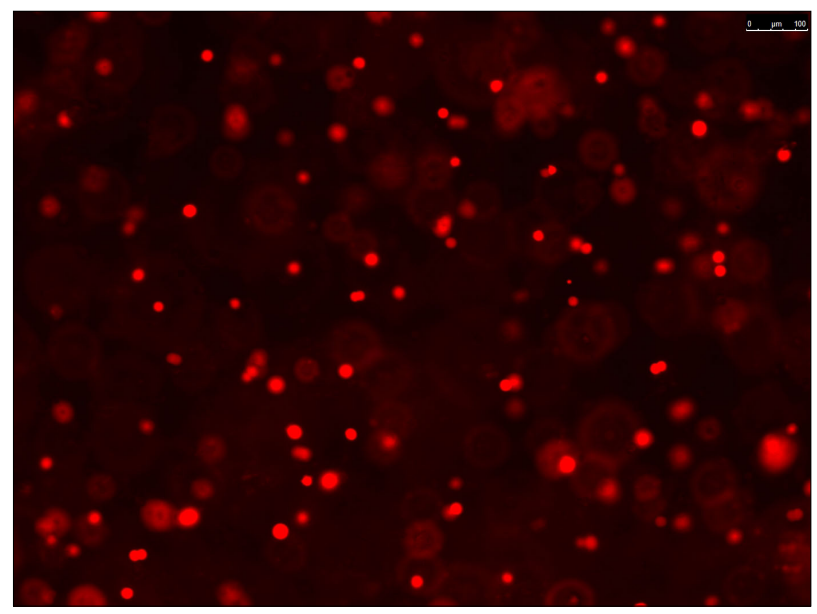

Fig. 3. $3 \mathrm{D}$ printed hepatic structure was made by $3 \mathrm{D}$ bioprinting machine. RFP expressing HepG2 cells were alive in the $3 \mathrm{D}$ printed hepatic structure for over 7 days (magnification; x200). 
cells and endothelial cells (84). Other research groups including us have used the solid free-form fabrication technique to print an organized 3D architecture of alginate-encapsulated HepG2 cells including growth factors and scaffold materials (Fig. 3) (85). The development of artificial livers seems feasible given the rapid progress in tissue engineering and bioprinting techniques.

\section{Conclusions and perspectives}

So far, the ultimate treatment for liver diseases has been liver transplantation, which has the problem of donor organ shortage and high costs. In order to lighten the burden and bridge the gap until a donor liver appears, or even to create alternative treatments, hepatocyte transplantation, liver support systems and $3 \mathrm{D}$ organ printing are being studied. The clinical need for healthy functional hepatocytes, not only for correcting metabolic liver diseases but also for treating acute liver failure and chronic liver diseases such as hepatocellular carcinoma and liver cirrhosis, has led researchers to focus on identifying eligible cell sources. Primary adult hepatocytes were among the first to be used, but now hepatocyte-like cells directly differentiated from cells of non-hepatic origin are being investigated. The functional efficacy and safety of candidate cells is the main issue in terms of finding adequate cell sources, on top of the ability to culture functional differentiated cells on a large scale. We need to understand in more detail the fundamental molecular pathways involved in the differentiation of hepatocytes and cholangiocytes from stem/progenitor cells, as well as the factors that are responsible for the in vitro differentiation of various types of stem cell into hepatocytes. The role of oval cells in response to liver injury and the issue of their status as hepatic stem/progenitor cells must be clarified. In order to achieve functionally stable isolated in vitro hepatocytes systems, we may anticipate the development of co-culture models and 3D extracellular matrices. The paucity of safe and functionally active sources of hepatic cells, and the considerable expense involved, have held back the wider clinical application of BALs, and created a need for more physiologic ways for the cells to make contact with patients' plasma. Consequently, bioengineering has claimed a role in the liver regeneration field and the treatment of liver diseases by providing decellularization-recellularization methods for maintaining the anatomical structure of organs, and allowing hepatic cells to form physiological contacts. Further advance in the safety and clinical relevance of this technology are to be expected. The even more advanced technology of 3D bio- printing raises the hope of being able to actually print functional artificial livers. More enrichment in bioengineering and in basic understanding of the differentiation of stem cells into hepatocytes will complete the building blocks required for developing alternatives to liver transplantation.

\section{Acknowledgments}

This work was carried out with the support of "Cooperative Research Program for Agriculture Science \& Technology Development (Project No. PJ0110022015)" Rural Development Administration, Republic of Korea.

\section{Potential conflict of interest}

The authors have no conflicting financial interest.

\section{References}

1. Monga SPS. Molecular pathology of liver disease. In: Cagle PT, editor. Molecular pathology library. New York: Springer; 2011. 7-25

2. Lopez AD, Mathers CD, Ezzati M, Jamison DT, Murray CJL. Measuring the global burden of disease and risk factors, 1990-2001. In: Lopez AD, Disease Control Priorities Project, editor. Global burden of disease and risk factors. Washington, DC: World Bank Publications; 2006. 1-14

3. Matz P, Adjaye J. Characterisation of human induced pluripotent stem cell-derived hepatocyte like cells and endodermal progenitors. European Journal of Medical Research 2014;19 Suppl 1:S8

4. Dhawan A, Puppi J, Hughes RD, Mitry RR. Human hepatocyte transplantation: current experience and future challenges. Nat Rev Gastroenterol Hepatol 2010;7:288-298

5. LeCluyse EL. Human hepatocyte culture systems for the in vitro evaluation of cytochrome P450 expression and regulation. Eur J Pharm Sci 2001;13:343-368

6. Yovchev MI, Xue Y, Shafritz DA, Locker J, Oertel M. Repopulation of the fibrotic/cirrhotic rat liver by transplanted hepatic stem/progenitor cells and mature hepatocytes. Hepatology 2014;59:284-295

7. Komori J, Boone L, DeWard A, Hoppo T, Lagasse E. The mouse lymph node as an ectopic transplantation site for multiple tissues. Nat Biotechnol 2012;30:976-983

8. Soltys KA, Soto-Gutiérrez A, Nagaya M, Baskin KM, Deutsch M, Ito R, Shneider BL, Squires R, Vockley J, Guha C, Roy-Chowdhury J, Strom SC, Platt JL, Fox IJ. Barriers to the successful treatment of liver disease by hepatocyte transplantation. J Hepatol 2010;53:769-774

9. Hughes RD, Mitry RR, Dhawan A. Current status of hepatocyte transplantation. Transplantation 2012;93:342-347

10. Sahi J, Grepper S, Smith C. Hepatocytes as a tool in drug metabolism, transport and safety evaluations in drug discovery. Curr Drug Discov Technol 2010;7:188-198

11. Allen KJ, Mifsud NA, Williamson R, Bertolino P, Hardikar 
W. Cell-mediated rejection results in allograft loss after liver cell transplantation. Liver Transpl 2008;14:688-694

12. Schwartz RE, Verfaillie C. Hepatic stem cells. Methods Mol Biol 2010;640:167-179

13. Nagata H, Nishitai R, Shirota C, Zhang JL, Koch CA, Cai J, Awwad M, Schuurman HJ, Christians U, Abe M, Baranowska-Kortylewicz J, Platt JL, Fox IJ. Prolonged survival of porcine hepatocytes in cynomolgus monkeys. Gastroenterology 2007;132:321-329

14. Gupta S. Hog heaven on the road to liver cell therapy. Gastroenterology 2007;132:450-453

15. Yang Q, Liu F, Pan XP, Lv G, Zhang A, Yu CB, Li L. Fluidized-bed bioartificial liver assist devices (BLADs) based on microencapsulated primary porcine hepatocytes have risk of porcine endogenous retroviruses transmission. Hepatol Int 2010;4:757-761

16. te Velde AA, Flendrig LM, Ladiges NC, Chamuleau RA. Immunological consequences of the use of xenogeneic hepatocytes in a bioartificial liver for acute liver failure. Int J Artif Organs 1997;20:229-233

17. Krebs N, Neville C, Vacanti JP. Cellular transplants for liver diseases. In: Halberstadt C, Emerich DF, editor. cellular transplantation: from laboratory to clinic. Burlington, MA: AcademicPress; 2011. 215-240

18. Sussman NL, Chong MG, Koussayer T, He DE, Shang TA, Whisennand HH, Kelly JH. Reversal of fulminant hepatic failure using an extracorporeal liver assist device. Hepatology 1992;16:60-65

19. Tsiaoussis J, Newsome PN, Nelson LJ, Hayes PC, Plevris JN. Which hepatocyte will it be? Hepatocyte choice for bioartificial liver support systems. Liver Transpl 2001;7:2-10

20. Ellis AJ, Hughes RD, Wendon JA, Dunne J, Langley PG, Kelly JH, Gislason GT, Sussman NL, Williams R. Pilotcontrolled trial of the extracorporeal liver assist device in acute liver failure. Hepatology 1996;24:1446-1451

21. Mazariegos GV, Patzer JF 2nd, Lopez RC, Giraldo M, Devera ME, Grogan TA, Zhu Y, Fulmer ML, Amiot BP, Kramer DJ. First clinical use of a novel bioartificial liver support system (BLSS). Am J Transplant 2002;2:260-266

22. Li J, Li LJ, Cao HC, Sheng GP, Yu HY, Xu W, Sheng JF. Establishment of highly differentiated immortalized human hepatocyte line with simian virus 40 large tumor antigen for liver based cell therapy. ASAIO J 2005;51:262-268

23. Kobayashi N, Okitsu T, Tanaka N. Cell choice for bioartificial livers. Keio J Med 2003;52:151-157

24. Yoon JH, Lee HV, Lee JS, Park JB, Kim CY. Development of a non-transformed human liver cell line with differentiated-hepatocyte and urea-synthetic functions: applicable for bioartificial liver. Int J Artif Organs 1999;22: 769-777

25. Deurholt T, van Til NP, Chhatta AA, ten Bloemendaal L, Schwartlander R, Payne C, Plevris JN, Sauer IM, Chamuleau RA, Elferink RP, Seppen J, Hoekstra R. Novel immortalized human fetal liver cell line, cBAL111, has the potential to differentiate into functional hepatocytes. BMC Biotechnol 2009;9:89
26. Poyck PP, van Wijk AC, van der Hoeven TV, de Waart DR, Chamuleau RA, van Gulik TM, Oude Elferink RP, Hoekstra R. Evaluation of a new immortalized human fetal liver cell line (cBAL111) for application in bioartificial liver. J Hepatol 2008;48:266-275

27. Poyck PP, Hoekstra R, van Wijk AC, Attanasio C, Calise F, Chamuleau RA, van Gulik TM. Functional and morphological comparison of three primary liver cell types cultured in the AMC bioartificial liver. Liver Transpl 2007;13: 589-598

28. Chen Y, Li J, Liu X, Zhao W, Wang Y, Wang X. Transplantation of immortalized human fetal hepatocytes prevents acute liver failure in $90 \%$ hepatectomized mice. Transplant Proc 2010;42:1907-1914

29. Diekmann S, Bader A, Schmitmeier S. Present and Future Developments in Hepatic Tissue Engineering for Liver Support Systems : State of the art and future developments of hepatic cell culture techniques for the use in liver support systems. Cytotechnology 2006;50:163-179

30. Fausto N, Campbell JS. The role of hepatocytes and oval cells in liver regeneration and repopulation. Mech Dev 2003;120:117-130

31. Santoni-Rugiu E, Jelnes P, Thorgeirsson SS, Bisgaard HC. Progenitor cells in liver regeneration: molecular responses controlling their activation and expansion. APMIS 2005; 113:876-902

32. Evarts RP, Nagy P, Nakatsukasa H, Marsden E, Thorgeirsson SS. In vivo differentiation of rat liver oval cells into hepatocytes. Cancer Res 1989;49:1541-1547

33. Coleman WB, McCullough KD, Esch GL, Faris RA, Hixson DC, Smith GJ, Grisham JW. Evaluation of the differentiation potential of WB-F344 rat liver epithelial stemlike cells in vivo. Differentiation to hepatocytes after transplantation into dipeptidylpeptidase-IV-deficient rat liver. Am J Pathol 1997;151:353-359

34. Wang X, Foster M, Al-Dhalimy M, Lagasse E, Finegold $M$, Grompe $M$. The origin and liver repopulating capacity of murine oval cells. Proc Natl Acad Sci U S A 2003;100 Suppl 1:11881-11888

35. Sell S. Heterogeneity and plasticity of hepatocyte lineage cells. Hepatology 2001;33:738-750

36. Grompe M. Liver stem cells, where art thou? Cell Stem Cell 2014;15:257-258

37. Lagasse E, Connors H, Al-Dhalimy M, Reitsma M, Dohse M, Osborne L, Wang X, Finegold M, Weissman IL, Grompe M. Purified hematopoietic stem cells can differentiate into hepatocytes in vivo. Nat Med 2000;6:1229-1234

38. Wang X, Willenbring $\mathrm{H}$, Akkari Y, Torimaru Y, Foster M, Al-Dhalimy M, Lagasse E, Finegold M, Olson S, Grompe $M$. Cell fusion is the principal source of bone-marrow-derived hepatocytes. Nature 2003;422:897-901

39. Lee KD, Kuo TK, Whang-Peng J, Chung YF, Lin CT, Chou SH, Chen JR, Chen YP, Lee OK. In vitro hepatic differentiation of human mesenchymal stem cells. Hepatology 2004;40:1275-1284

40. Petrie Aronin CE, Tuan RS. Therapeutic potential of the 
immunomodulatory activities of adult mesenchymal stem cells. Birth Defects Res C Embryo Today 2010;90:67-74

41. Chang YJ, Liu JW, Lin PC, Sun LY, Peng CW, Luo GH, Chen TM, Lee RP, Lin SZ, Harn HJ, Chiou TW. Mesenchymal stem cells facilitate recovery from chemically induced liver damage and decrease liver fibrosis. Life Sci 2009;85:517-525

42. Aurich I, Mueller LP, Aurich H, Luetzkendorf J, Tisljar K, Dollinger MM, Schormann W, Walldorf J, Hengstler JG, Fleig WE, Christ B. Functional integration of hepatocytes derived from human mesenchymal stem cells into mouse livers. Gut 2007;56:405-415

43. di Bonzo LV, Ferrero I, Cravanzola C, Mareschi K, Rustichell D, Novo E, Sanavio F, Cannito S, Zamara E, Bertero M, Davit A, Francica S, Novelli F, Colombatto S, Fagioli F, Parola M. Human mesenchymal stem cells as a two-edged sword in hepatic regenerative medicine: engraftment and hepatocyte differentiation versus profibrogenic potential. Gut 2008;57:223-231

44. Aurich H, Sgodda M, Kaltwasser P, Vetter M, Weise A, Liehr T, Brulport M, Hengstler JG, Dollinger MM, Fleig WE, Christ B. Hepatocyte differentiation of mesenchymal stem cells from human adipose tissue in vitro promotes hepatic integration in vivo. Gut 2009;58:570-581

45. Piryaei A, Valojerdi MR, Shahsavani M, Baharvand H. Differentiation of bone marrow-derived mesenchymal stem cells into hepatocyte-like cells on nanofibers and their transplantation into a carbon tetrachloride-induced liver fibrosis model. Stem Cell Rev 2011;7:103-118

46. Jalan R, Williams R. Acute-on-chronic liver failure: pathophysiological basis of therapeutic options. Blood Purif 2002;20:252-261

47. Chamuleau RA, Deurholt T, Hoekstra R. Which are the right cells to be used in a bioartificial liver? Metab Brain Dis 2005;20:327-335

48. Payne CM, Samuel K, Pryde A, King J, Brownstein D, Schrader J, Medine CN, Forbes SJ, Iredale JP, Newsome PN, Hay DC. Persistence of functional hepatocyte-like cells in immune-compromised mice. Liver Int 2011;31:254-262

49. Müller LU, Daley GQ, Williams DA. Upping the ante: recent advances in direct reprogramming. Mol Ther 2009;17: 947-953

50. Shan J, Schwartz RE, Ross NT, Logan DJ, Thomas D, Duncan SA, North TE, Goessling W, Carpenter AE, Bhatia SN. Identification of small molecules for human hepatocyte expansion and iPS differentiation. Nat Chem Biol 2013; 9:514-520

51. Liu H, Kim Y, Sharkis S, Marchionni L, Jang YY. In vivo liver regeneration potential of human induced pluripotent stem cells from diverse origins. Sci Transl Med 2011;3: 82 ra39

52. Yu YD, Kim KH, Lee SG, Choi SY, Kim YC, Byun KS, Cha IH, Park KY, Cho CH, Choi DH. Hepatic differentiation from human embryonic stem cells using stromal cells. J Surg Res 2011;170:e253-e261

53. Sekiya S, Suzuki A. Direct conversion of mouse fibroblasts to hepatocyte-like cells by defined factors. Nature 2011; 475:390-393

54. Huang P, He Z, Ji S, Sun H, Xiang D, Liu C, Hu Y, Wang $\mathrm{X}$, Hui L. Induction of functional hepatocyte-like cells from mouse fibroblasts by defined factors. Nature 2011;475: 386-389

55. Huang $\mathrm{P}$, Zhang L, Gao Y, He Z, Yao D, Wu Z, Cen J, Chen X, Liu C, Hu Y, Lai D, Hu Z, Chen L, Zhang Y, Cheng X, Ma X, Pan G, Wang X, Hui L. Direct reprogramming of human fibroblasts to functional and expandable hepatocytes. Cell Stem Cell 2014;14:370-384

56. Du Y, Wang J, Jia J, Song N, Xiang C, Xu J, Hou Z, Su $\mathrm{X}$, Liu B, Jiang T, Zhao D, Sun Y, Shu J, Guo Q, Yin M, Sun D, Lu S, Shi Y, Deng H. Human hepatocytes with drug metabolic function induced from fibroblasts by lineage reprogramming. Cell Stem Cell 2014;14:394-403

57. Zhu S, Rezvani M, Harbell J, Mattis AN, Wolfe AR, Benet LZ, Willenbring H, Ding S. Mouse liver repopulation with hepatocytes generated from human fibroblasts. Nature 2014;508:93-97

58. Yu B, He ZY, You P, Han QW, Xiang D, Chen F, Wang MJ, Liu CC, Lin XW, Borjigin U, Zi XY, Li JX, Zhu HY, Li WL, Han CS, Wangensteen KJ, Shi Y, Hui LJ, Wang $\mathrm{X}, \mathrm{Hu}$ YP. Reprogramming fibroblasts into bipotential hepatic stem cells by defined factors. Cell Stem Cell 2013;13: 328-340

59. Malik R, Selden C, Hodgson H. The role of non-parenchymal cells in liver growth. Semin Cell Dev Biol 2002;13: 425-431

60. Maher JJ, Bissell DM. Cell-matrix interactions in liver. Semin Cell Biol 1993;4:189-201

61. Choi HJ, Choi D. Successful mouse hepatocyte culture with sandwich collagen gel formation. J Korean Surg Soc 2013; 84:202-208

62. Ansede JH, Smith WR, Perry CH, St Claire RL 3rd, Brouwer KR. An in vitro assay to assess transporter-based cholestatic hepatotoxicity using sandwich-cultured rat hepatocytes. Drug Metab Dispos 2010;38:276-280

63. Begue JM, Guguen-Guillouzo C, Pasdeloup N, Guillouzo A. Prolonged maintenance of active cytochrome P-450 in adult rat hepatocytes co-cultured with another liver cell type. Hepatology 1984;4:839-842

64. Rojkind M, Novikoff PM, Greenwel P, Rubin J, RojasValencia L, de Carvalho AC, Stockert R, Spray D, Hertzberg EL, Wolkoff AW. Characterization and functional studies on rat liver fat-storing cell line and freshly isolated hepatocyte coculture system. Am J Pathol 1995; 146:15081520

65. Bhatia SN, Balis UJ, Yarmush ML, Toner M. Effect of cell-cell interactions in preservation of cellular phenotype: cocultivation of hepatocytes and nonparenchymal cells. FASEB J 1999;13:1883-1900

66. Burkhardt B, Martinez-Sanchez JJ, Bachmann A, Ladurner $R$, NüsslerAK. Long-term culture of primary hepatocytes: new matrices and microfluidic devices. Hepatology International 2014;8:14-22 
67. Saliba F, Camus C, Durand F, Mathurin P, Delafosse B, Barange K, Perrigault PF, Revel P, Serfaty L, Belnard M, Letierce A, Ichai P, Samuel D. 220 Predictive factors of transplant free survival in patients with fulminant and subfulminant liver failure; results from a randomized controlled multicenter trial. J Hepatol 2009;50 Suppl 1:S89

68. Rifai K. Fractionated plasma separation and adsorption: current practice and future options. Liver Int 2011;31 Suppl 3:13-15

69. Rifai K, Ernst T, Kretschmer U, Bahr MJ, Schneider A, Hafer C, Haller H, Manns MP, Fliser D. Prometheus--a new extracorporeal system for the treatment of liver failure. J Hepatol 2003;39:984-990

70. Demetriou AA, Brown RS Jr, Busuttil RW, Fair J, McGuire BM, Rosenthal P, Am Esch JS 2nd, Lerut J, Nyberg SL, Salizzoni M, Fagan EA, de Hemptinne B, Broelsch CE, Muraca M, Salmeron JM, Rabkin JM, Metselaar HJ, Pratt D, De La Mata M, McChesney LP, Everson GT, Lavin PT, Stevens AC, Pitkin Z, Solomon BA. Prospective, randomized, multicenter, controlled trial of a bioartificial liver in treating acute liver failure. Ann Surg 2004;239:660-667

71. Ellis AJ, Hughes RD, Wendon JA, Dunne J, Langley PG, Kelly JH, Gislason GT, Sussman NL, Williams R. Pilot-controlled trial of the extracorporeal liver assist device in acute liver failure. Hepatology 1996;24:1446-1451

72. Sauer IM, Kardassis D, Zeillinger K, Pascher A, Gruenwald A, Pless G, Irgang M, Kraemer M, Puhl G, Frank J, Müller AR, Steinmüller T, Denner J, Neuhaus P, Gerlach JC. Clinical extracorporeal hybrid liver support--phase I study with primary porcine liver cells. Xenotransplantation 2003;10:460-469

73. van de Kerkhove MP, Di Florio E, Scuderi V, Mancini A, Belli A, Bracco A, Dauri M, Tisone G, Di Nicuolo G, Amoroso P, Spadari A, Lombardi G, Hoekstra R, Calise F, Chamuleau RA. Phase I clinical trial with the AMC-bioartificial liver. Int J Artif Organs 2002;25:950-959

74. Iwata H, Ueda Y. Pharmacokinetic considerations in development of a bioartificial liver. Clin Pharmacokinet 2004;43: 211-225

75. Bernard MP, Chu ML, Myers JC, Ramirez F, Eikenberry EF, Prockop DJ. Nucleotide sequences of complementary deoxyribonucleic acids for the pro alpha 1 chain of human type I procollagen. Statistical evaluation of structures that are conserved during evolution. Biochemistry 1983;22: 5213-5223

76. Crapo PM, Gilbert TW, Badylak SF. An overview of tissue and whole organ decellularization processes. Biomaterials 2011;32:3233-3243

77. Uygun BE, Soto-Gutierrez A, Yagi H, Izamis ML, Guzzardi MA, Shulman C, Milwid J, Kobayashi N, Tilles A, Berthiaume F, Hertl M, Nahmias Y, Yarmush ML, Uygun $\mathrm{K}$. Organ reengineering through development of a transplantable recellularized liver graft using decellularized liver matrix. Nat Med 2010;16:814-820

78. Soto-Gutierrez A, Zhang L, Medberry C, Fukumitsu K, Faulk D, Jiang H, Reing J, Gramignoli R, Komori J, Ross M, Nagaya M, Lagasse E, Stolz D, Strom SC, Fox IJ, Badylak SF. A whole-organ regenerative medicine approach for liver replacement. Tissue Eng Part C Methods 2011;17: 677-686

79. Baptista PM, Siddiqui MM, Lozier G, Rodriguez SR, Atala A, Soker S. The use of whole organ decellularization for the generation of a vascularized liver organoid. Hepatology 2011;53:604-617

80. Barakat O, Abbasi S, Rodriguez G, Rios J, Wood RP, Ozaki C, Holley LS, Gauthier PK. Use of decellularized porcine liver for engineering humanized liver organ. J Surg Res 2012;173:e11-e25

81. Guillemot F, Mironov V, Nakamura M. Bioprinting is coming of age: Report from the International Conference on Bioprinting and Biofabrication in Bordeaux (3B'09). Biofabrication 2010;2:010201

82. Klebe RJ. Cytoscribing: a method for micropositioning cells and the construction of two- and three-dimensional synthetic tissues. Exp Cell Res 1988;179:362-373

83. Mironov V, Visconti RP, Kasyanov V, Forgacs G, Drake CJ, Markwald RR. Organ printing: tissue spheroids as building blocks. Biomaterials 2009;30:2164-2174

84. Robbins JB, Gorgen V, Min P, Shepherd BR, Presnell SC. A novel in vitro three-dimensional bioprinted liver tissue system for drug development FASEB J 2013;27(Meeting Abstract Supplement):872.12

85. Chang R, Emami K, Wu H, Sun W. Biofabrication of a three-dimensional liver micro-organ as an in vitro drug metabolism model. Biofabrication 2010;2:045004 